\title{
Differences in impulsivity between females diagnosed with eating disorders and healthy subjects
}

\begin{abstract}
Objectives: This cross-sectional study investigates the tendencies toward impulsivity and self-control over the entire spectrum of the different eating disorders in comparison to healthy and recovered subjects.

Methods: The study included 116 women, aged 18-35. Participants filled seven self-report questionnaires to assess eating disorders features and tendencies toward impulsivity and self-control and two computerized tasks (Go/No Go and Cognitive Delay Discounting) to examine motoric impulsivity.

Results: There was a hierarchy of occurrence of impulsivity in the different categories of eating disorders. Cognitive impulsivity as well as motor impulsivity and global score of impulsivity were most prominent in the anorexia nervosa binging type. This hierarchy was correlated with the eating disorders symptoms. The lowest score in motor impulsivity was observed among restrictive patients with anorexia and the highest among patients with binging-purging anorexia, while all other groups were in between. Those with bingingpurging anorexia demonstrated significantly different behavior in short term delays: they were less willing to delay gratification in comparison to other participants who demonstrated preference for the higher delayed reward. The impulse regulation and the ineffectiveness scores of both anorextic groups were higher in comparison to the other groups. These two variables were highly correlated with attentional impulsiveness.
\end{abstract}

Conclusion: These findings suggest that bingeing and restricting behaviors may be seen as lying on opposite ends of a spectrum of impulsive behaviors. Individuals with AN-BP appear to have more in common with BN individuals as they share the tendency to display greater response Disinhibition and produce more impulsive behaviors. Since at this stage only a small sample size was analyzed these results are considered preliminary.
Volume 3 Issue 3 - 2015

\author{
Langer M, ${ }^{1,2,3}$ Bord A, ${ }^{4}$ Golan $\mathrm{M}^{1,2,3}$ \\ 'Tel Hai Academic College, Department of nutrition, Israel \\ ${ }^{2}$ The Hebrew University of Jerusalem, School of Nutritional \\ Sciences, Israel \\ ${ }^{3}$ Shahaf, Community Services for the Management of Weight- \\ Related Problems, Israel \\ ${ }^{4}$ The Hebrew University of Jerusalem, Department of \\ Psychology, Israel
}

Correspondence: Golan Moria, Department of nutrition, Tel Hai Academic College, Israel, Tel 972-544378666, Fax 97,28,93,48,798, Email moria.golan@mail.huji.ac.il

Received: July 09, 2015 | Published: August 15, 2015

Keywords: impulsivity, self- control, eating disorders

\section{Introduction}

Over the past decade, a growing body of literature suggests that eating disorders (EDs), and, in particular, those with binging features (anorexia binge purging type, bulimia nervosa and binge eating disorder) are associated with impulsive behavior along with a lack of self-control and self-regulation. In addition to abnormal eating behaviors and cognitive distortion in terms of weight and body image (American Psychiatric Association, 2000), EDs are also often associated with other impulsive behaviors, ${ }^{1}$ such as compulsive buying self-injury, shoplifting, alcohol abuse, sexual promiscuity. Only few studies examined impulsivity and self-control among all subtypes of ED's in comparison to healthy subjects. The current research aims to address this gap.

When locating ED's on the weight axis, EDs subtypes range from the anorexia nervosa (AN) at the one extreme of the weight axis, characterized by underweight and those with binge-eating disorder (BED) at the other extreme of the weight axis, typified as overweight or obese. Although differing in weight status, these subtypes share common characteristics, thus it is not surprising that often patients' diagnosis shifts between the disorders. Understanding the role of impulsivity and self-control in each of these subtypes might assist in diminishing the fog around this shifting and contribute to understanding of ED's etiology as well as highlight therapeutic possibilities.

Impaired self-regulation skills, impulsive behavior and poor decision making, have been proposed as etiological and therapeutic targets in ED. ${ }^{2,3}$ The interest in studying self-regulation and decision making in EDs lies on ${ }^{4}$ clinical consideration suggesting a behavior of immediate reward seeking despite often severe longterm psychological and medical consequences in anorexia (behavior restriction and starvation give immediate reward through the relief of anxiety or tension), bulimia (immediate benefit of purging) and Binge Eating Disorder (compulsive overeating), ${ }^{5}$ the neuroanatomical consideration suggests that the key regions in decision making are implicated in Eds, ${ }^{3}$ and last, ${ }^{6}$ the serotonergic system possibly involved in $\mathrm{Eds}^{3}$ seem to modulate decision making.

Lower decision making capacity had been reported in patients with anorexia ${ }^{8,9}$ as well as bulimia ${ }^{10-12}$ and BED. ${ }^{13,14}$ High capacity of decision making is associated with higher self- regulation.

Self-regulation is the individual's ability to control one's behaviors in an efficient and appropriate manner. It is a cognitive process essential for behavioral control, taking into consideration internal and external demands. ${ }^{15}$ This ability is structured by a chain of events, which guide behavior. First, there is an external stimulus, an impulse arising from a global motivation e.g. hunger, thirst, stress, fear, possessing a strong incentive value consisting of a primitive hedonic reaction. ${ }^{16}$ It is immediate in a temporal and spatial sense and typically involves an inclination to perform a certain short-term behavior.

The primary reaction to the stimulus depends on two components: its intensity and the individual sensitivity differing according to various personality characteristics e.g. novelty seeking ${ }^{17}$ and situational factors e.g. state of drive for thinness, dietary restrictions. 
An impulsive reaction might be adaptive if we were living for the moment without concern for the well-being of others. But most impulsive, un-regulated behaviors disturb long-term goals and create interpersonal conflicts. Therefore, we need the ability to inhibit automatic, impulsive reaction. At this point, evaluation of reaction outcomes is activated, and a preferable behavior is chosen. ${ }^{18}$ After the action itself, a sense of a positive reward is expected, either due to the immediate satisfaction or its successful rejection for the sake of preferential long-term. ${ }^{19}$

The Dual-system model of impulse-regulation ${ }^{16}$ suggests that behavior is determined by two parallel and competing systems. The impulsive system emerges from the activation of certain associative clusters in long-term memory by perceptual or imagined stimulus input. This activation strengthens the learned association between the external stimuli, affective reactions, and associated behavioral tendencies. By contrast, the reflective system serves regulatory goals and responsible for higher order mental operations, including judgment, evaluation, planning and inhibition. The reflective system thus provides a flexible, higher-order control over decisions and actions through which immediate stimulus control can be overcome. The operations of the reflective system depended on cognitive resources. If available resources are low, reflective operations may break down. And the question remains: Which of the two systems will gain control over actual behavior in the end? The answer depends on the relative strength of the behavioral schema triggered by each system. Self-regulation inhibits automatic impulsive reactions. ${ }^{16}$

Patton et al., ${ }^{20}$ distinct three main dimensions of impulsivity (1) motor impulsiveness; (2) attentional impulsiveness; and (3) nonplanning impulsiveness. Within these dimensions, the ones that were successfully replicated and on which we will focus in the proposed research, are the motor and attentional or cognitive impulsivity.

Correlations have been found between ED and impulsivity levels. Women with bulimia nervosa showed higher levels of impulsivity compared to women with anorexia nervosa. Among patients with anorexia those with binge purging type patients showed higher levels of impulsivity compared to restricting type patients. ${ }^{21}$ To the best of our knowledge, to date, there are no publications comparing all ED's subtypes to healthy populations' performance on tasks to evaluate distinct impulsivity dimensions.

Waxman ${ }^{22}$ reviewed 12 studies conducted within the last decade and indicated a number of marked limitations which require future treatment: (1) lack of a matched control group; (2) insufficient evaluation of impulsivity levels; (3) lack of sample characteristics description e.g. age, gender, and ethnicity; and (4) lack of accurate ED definitions. The proposed research will address the mentioned limitations.

The proposed research aims to examine the relationship between impulsivity and self-control, symptoms, behaviors and diagnoses of women with different subtypes of EDs. Motoric and cognitive impulsivity and their relationships with self-control, symptomatic behaviors, weight status and diagnosis have been examined. The special contribution of our study is that unlike previous ones, it examined the tendencies toward impulsivity and self-control over the entire spectrum of the different weight disorders- anorexia nervosa, bulimia nervosa and binge eating disorder, and compared them to those of healthy subjects. Understanding these differences may contribute to a deeper understanding of the etiology of the various EDs specifically, the ability to predict risk of developing EDs while helping to formulate more targeted treatment system for the various EDs (as was diagnosed using DSM-IV). Those that suffer from binge purge type with sever impulsivity might gain from more self-control training while those that suffer from restriction and emotion-regulation features might need more emphasize on emotional self- regulation rather self-control. Moreover, we tested whether these parameters could be used as criteria to distinguish between the different diagnosis groups.

\section{Materials and methods}

The proposed research was approved by Herzog Hospital and The Ministry of Health Helsinki committees on October 2010. All participants provided written informed consent. Data were collected from January 2011 through September 2013.

\section{Participants}

Males were excluded from the current study because there were too few for meaningful comparisons. The sample of females diagnosed with ED consisted of 65 participants aged 18-35, ill or recovered at the time of the study. ED subjects were recruited from community based ED centers in Israel. Participants were sub typed as follows: AN restrictive type $(A N-R) n=11$; AN purging type (AN-BP) $n=10$; Bulimia nervosa (BN) $n=12$; Binge eating disorder (BED) $n=16$ and Recovered participants $n=16$. There were no Non-purging $B N$ in this sample. 51 healthy controls (HC) were recruited by announcements around the Hebrew University campus. Each subject participated in a 1-hour experiment which was honored with $10 \$$.

\section{Measures}

Participants height and weight were measured at the initial assessment appointment using a medical balance beam scale. To establish the ED diagnosis and core eating disorder symptoms, the structured clinical interview for DSM-IV axis I disorders was administered. ${ }^{23}$ Additional eating disorder symptoms were assessed using the eating disorder inventory- 2 .

$\mathrm{EDI}-2,{ }^{24}$ is a 91 -item self-report questionnaire assessing attitudes and behaviors characterizing ED. The EDI-2 yields 11 sub-scores: drive for thinness, perfectionism, bulimia, body dissatisfaction, ineffectiveness, social insecurity, introspective awareness, maturity fears, asceticism, impulse regulation, and interpersonal distrust. A total score is also given, and provides a standardized cut-off point to evaluate the presence/absence of an eating disorder. Sub-scores show moderately-good reliability Cronbach's alpha is $0.44-0.93$. Test-retest reliability is between $0.79-0.95$ for all sub-scores, except for introspective awareness. The EDI-2 has a Hebrew version which was found valid and reliable in a previous research. ${ }^{25}$ In our study Cronbach's alpha was $>0.80$.

Each subject also filled in questionnaires evaluating impulsivity levels: The Barratt Impulsiveness Scale (BIS-11), ${ }^{20}$ Self-Control Scale (SCS), and MPQ-Impulsivity/Control Sub-scale; and performed two tasks: Delay Discounting and Go/No-Go. BIS- $11^{20}$ is a 30 -item selfreport questionnaire designed to assess the personality/behavioral construct of impulsivity. It yields (1) Total score of 30-120; (2) 6 first-order scores: attention "focusing on the task at hand", motor impulsiveness "acting on the spur of the moment", self-control "planning and thinking carefully", cognitive complexity "enjoy challenging mental tasks", perseverance "a consistent life style", and cognitive instability "thought insertions and racing thoughts"; and (3) 3 second-order factors: attentional impulsiveness combines attention and cognitive instability factors, motor impulsiveness combines motor impulsiveness and perseverance factors, and non-planning impulsiveness combines self-control and cognitive complexity factors. Previous research reported moderately-good 
reliability Cronbach's alpha $=0.79$ of the Hebrew version of BIS$11 .{ }^{26}$ In addition, the BIS-11 was found to efficiently distinguish healthy and clinical populations, such as bi-polar disorder patients, Borderline personalities and kleptomaniacs. It is correlated with other neuropsychological impulsivity measures, such as the "false alarm index" of the Go/No-Go task. ${ }^{27}$

Self-control scale $(\mathrm{SCS})^{28}$ is a 36 -item self-report questionnaire evaluating the individual's self-control ability, as expressed by breaking habits, resisting temptation, and maintaining good self-discipline. Previous study reported good internalconsistency reliability Cronbach's alpha $=0.89$ and also testretest reliability of $0.89 .{ }^{28}$ For the proposed study, the English scale was translated into Hebrew and Cronbach's alpha $=0.85$ MPQ - Impulsivity/control sub-scale ${ }^{29}$ is a 300 -"true/false"-item selfreport questionnaire that yields 11 personality dimensions. We have used the Impulsivity/control sub-scale only which evaluates, for example, caution, rationality, detailed planning. Previous research indicated good internal-consistency reliability Cronbach's alpha between $0.8-0.86$. In addition, good internal-consistency reliability was found in the Hebrew version. ${ }^{30}$ In our study Cronbach's alpha was $>0.82$.

Delay discounting DD ${ }^{31}$ is a term typically used to describe the devaluation of rewards over time. Much research across a wide variety of domains has illustrated that people in general prefer a smaller reward delivered soon as opposed to a larger reward delivered at a later stage. This measure is significantly correlated with other impulsivity measures. It was "borrowed" from the neuro-economics field, and used to predict a wide range of decision-making behaviors, beyond purely economic decisions. The subject is asked to make a series of choices. In each trial, the subject chooses between two amounts of money in the proposed research the amounts will be 4- 40 NIS, in accordance with accepted amounts from previous studies in US dollars, one is immediate and the other is delayed. The delayed amount can be equal to or greater than the immediate one, and the delay time for receiving it changes randomly from one to ninety days. The task is computerized. This model's aim is to detect "indifference points" for each interval, in which one's subjective value of both the immediate and the delayed amounts is equal, and he/she does not prefer one over the other. ${ }^{32}$ By estimating a series of these indifference points for different delays, a subjective value curve can be plotted for each group. The resulting curve's gradient indexes the rate at which the value of the delayed amount is discounted as a function of the delay, i.e. discount rate. Steeper curve gradients represent higher discounting rate and stronger impulsive-choice tendency. To assess discounting rate, a hyperbolic equation was fitted: ${ }^{33}$ where V-Represents the value of the delayed item indexed by the indifference point, $\mathrm{M}$ - Represents the amount of money available from the immediate item ${ }^{40}$ NIS in the proposed research, D-Represents the length of the delay and $\mathrm{K}$ - Is a fitted parameter indexing discounting rate. Go/No-Go. ${ }^{34}$ In this paradigm the subject is being presented with a series of stimuli and is asked to react each time a go-stimulus is presented and avoid reaction each time a no-go-stimulus is presented. The subject's reaction is a simple motor one-quickly pressing a key when a go-stimulus is presented. Stimuli mapping as go and no-go stimuli is explained at the beginning and is changed once during the task. This paradigm assesses motor response-inhibition capability, essential for cognitive flexibility and behavioral accommodation to environmental changes, and varies interpersonally. Inhibiting control is measured by frequent "false alarm" reactions, which are pressing the key while a no-go stimulus is being presented. The higher the "false alarm" frequency, the lower the subject's capability of inhibiting motor reactions. ${ }^{35}$ In the proposed research we use a computerized Go/No-Go, in which stimuli 1, 2, 3, and 4 are presented in four 25-trial blocks. Each stimulus is presented for $500 \mathrm{~ms}$ and between-stimuli interval is randomly changed between $200,400,600,800$, and $1000 \mathrm{~ms}$. In the first two blocks, the subject is asked to react whenever the digits 1 or 2 appear and not to react whenever 3 or 4 appear. In blocks 3 and 4 , the instructions are reversed. Go-stimulus appearance frequency is $30 \%$ in each block.

While the Delay Discounting was found relevant to the "impulse decision-making" component, which involves conscious selection to evaluate outcomes The Go/No-Go was found relevant to the "impulse Disinhibition" component.

\section{Data Analyses}

Data analysis was performed using SPSS Statistics 17.0 and $\pi$ face software. Results are reported as means \pm SD. KolmogorovSmirnov $\mathrm{z}$ test showed that all variables, except Delay Discounting (DD) scores, had normal distribution. DD scores presented normality after computed to logarithm scale. To assess the association between the weight status and impulsivity/self-control, the BMI of participants was divided into three categories: $\mathrm{BMI}<18.5 ; 18.5 \leq \mathrm{BMI} \leq 25$ and BMI $>25$.

According to median of the BIS score two categories of selfcontrol were defined: high self-control BIS $\leq 63$ and low self- control/ impulsivity BIS $>63$.

Independent $\mathrm{T}$ tests were used to compare between the two selfcontrol categories. One-way ANOVA and post-hoc Turkey tests were used to compare the means of the continuous variables while $\chi 2$ tests were used to investigate the relation between the categorical variables. In addition, correlations between the self- control, impulsivity scores and the measures of eating psychopathology were examined using Pearson correlations.

\section{Results}

\section{Characteristics of studied population}

Anthropometric characteristics, age, illness and treatment outcome of the studies population are presented in Table 1. There were no differences in age at onset of participants' illness in the different groups of diagnosis. The average age is mid adolescent, in the range of 15-16years of age. Altogether, the longest duration of illness was in the BED group and the lowest in the Recovery group. At baseline there were significant statistical differences in the mean age of participants in the diagnosis groups with those with BED presenting the older age and those with anorexia nervosa restricting type as well as recovered patients were the youngsters (BED>BN-P/ Healthy Control/AN-BP $>$ AN-R/Recovered). In addition, a significant difference was found in BMI between the groups in Body Mass Index $(\mathrm{BMI}=\mathrm{Kg} / \mathrm{m} 2)$ status, age at illness' onset, duration of illness and duration of therapy. The highest BMI was in the BED subgroup. Since all ill participants were assessed during their outpatient program and since the duration of current treatment was the longest in the AN-R and Recovered participants, it is not surprising that no significant distinction was found in BMI between the healthy participants (HC group) and the AN-R, AN-BP, BN and Recovery group. The highest dropout rate was detected in AN-BP. Eating disorder symptoms are presented in Table 2. Significant statistic differences were found between the groups regarding all 11 tested indexes. AN-BP gained the highest scores while the healthy subjects the lowest. 
Table I Characteristics of studied population

\begin{tabular}{|c|c|c|c|c|c|c|c|}
\hline HC & AN-R & AN-BP & $\mathbf{B N}$ & Recovery & BED & Total & $\mathbf{p}$ \\
\hline$(n=5 I)$ & $(n=I I)$ & $(n=10)$ & $(n=12)$ & $(n=16)$ & $(n=16)$ & $(n=108)$ & \\
\hline \multicolumn{8}{|l|}{ Age } \\
\hline $24.5 I \pm 2.16 \mathrm{ab}$ & $22.91 \pm 5.48 \mathrm{a}$ & $24.30 \pm 5.18 \mathrm{ab}$ & $24.17 \pm 5.30 \mathrm{ab}$ & $23.13 \pm 4.88 a$ & $28.19 \pm 6.53 b$ & $24.73 \pm 4.48$ & 0.022 \\
\hline \multicolumn{8}{|l|}{ Wight (kg) } \\
\hline $56.98 \pm 5.23 a$ & $52.39 \pm 7.28 \mathrm{a}$ & $52.89 \pm 6.09 a$ & $58.5 \mathrm{I} \pm 5.03 \mathrm{a}$ & $57.64 \pm 5.66 a$ & $91.66 \pm 19.63 b$ & $61.49 \pm 15.58$ & $<0.001$ \\
\hline \multicolumn{8}{|l|}{ High (m) } \\
\hline $1.63 \pm 0.65$ & $1.63 \pm 0.86$ & $1.63 \pm 0.47$ & $1.64 \pm 0.40$ & $1.62 \pm 0.42$ & $1.63 \pm 0.57$ & $1.63 \pm 0.60$ & NS \\
\hline \multicolumn{8}{|l|}{ BMI } \\
\hline $21.38 \pm 1.7 \mathrm{la}$ & $19.59 \pm 1.92 \mathrm{a}$ & $19.85 \pm 2.67 \mathrm{a}$ & $21.65 \pm 1.64 a$ & $22.02 \pm 1.94 a$ & $34.25 \pm 5.79 b$ & $23.04 \pm 5.48$ & $<0.001$ \\
\hline \multicolumn{8}{|c|}{ Age of the illness' onset } \\
\hline & $15.27 \pm 2.10$ & $16 \pm 2.10$ & $16 \pm 2.33$ & $16 \pm 3.07$ & $15.25 \pm 3.0$ & $15.65 \pm 2.5$ & NS \\
\hline \multicolumn{8}{|c|}{ Duration of illness (years) } \\
\hline & $7.64 \pm 4.63 \mathrm{ab}$ & $8.30 \pm 3.86 \mathrm{ab}$ & $8.17 \pm 4.23 \mathrm{ab}$ & $7.13 \pm 2.85 a$ & $12.94 \pm 5.84 b$ & $9.28 \pm 5.03$ & 0.012 \\
\hline \multicolumn{8}{|c|}{ Duration of current treatment(months) } \\
\hline & $33.21 \pm 25.48 \mathrm{ab}$ & $6.56 \pm 4.94 a$ & $17.13 \pm 17.3 \mathrm{a}$ & $44.43 \pm 30.20 b$ & --- & $23.09 \pm 24.04$ & 0.004 \\
\hline
\end{tabular}

Table 2 Participants scores in eating disorders inventory (EDI-2)

\begin{tabular}{|c|c|c|c|c|c|c|c|}
\hline $\begin{array}{l}\text { HC } \\
(n=5 I)\end{array}$ & $\begin{array}{l}\text { AN-R } \\
(n=9)\end{array}$ & $\begin{array}{l}\text { AN-BP } \\
(n=9)\end{array}$ & $\begin{array}{l}B N \\
(n=I I)\end{array}$ & $\begin{array}{l}\text { Recovery } \\
(n=\mid 5)\end{array}$ & $\begin{array}{l}\text { BED } \\
(n=16)\end{array}$ & $\begin{array}{l}\text { Total } \\
(n=103)\end{array}$ & $\mathbf{p}$ \\
\hline \multicolumn{8}{|c|}{ Social Insecurity } \\
\hline $1.84 \pm 2.2 \mathrm{Ia}$ & $6.22 \pm 6.26 \mathrm{abc}$ & $8.44 \pm 6.36 c$ & $6.00 \pm 4.89 \mathrm{abc}$ & $7.86 \pm 8.39 b c$ & $2.8 \mathrm{I} \pm 3.44 \mathrm{ab}$ & $3.8 I \pm 4.80$ & 0.001 \\
\hline \multicolumn{8}{|c|}{ Impulse Regulation } \\
\hline $1.27 \pm 2.27 \mathrm{a}$ & $8.00 \pm 7.4 \mathrm{Ib}$ & $8.22 \pm 8.95 b$ & $5.18 \pm 5.91 \mathrm{ab}$ & $4.00 \pm 4.76 \mathrm{ab}$ & $4.56 \pm 5.22 \mathrm{ab}$ & $3.58 \pm 5.35$ & $<0.001$ \\
\hline \multicolumn{8}{|l|}{ Asceticism } \\
\hline $2.04 \pm 2.0 \mathrm{la}$ & $7.22 \pm 7.10 \mathrm{ab}$ & $10.33 \pm 6.74 b$ & $8.18 \pm 5.82 b$ & $7.57 \pm 9.8 \mathrm{Iab}$ & $6.3 \mathrm{I} \pm 3.6 \mathrm{Iab}$ & $4.91 \pm 5.43$ & $<0.001$ \\
\hline \multicolumn{8}{|l|}{ Maturity Fears } \\
\hline $3.57 \pm 2.67 \mathrm{a}$ & $7.67 \pm 6.24 b$ & $7.1 I \pm 5.73 b$ & $7.55 \pm 6.20 b$ & $3.57 \pm \mathrm{I} .8 \mathrm{Ia}$ & $4.94 \pm 2.86 \mathrm{ab}$ & $4.87 \pm 4.14$ & $<0.001$ \\
\hline \multicolumn{8}{|c|}{ Introspective Awareness } \\
\hline $1.73 \pm 2.54 \mathrm{a}$ & $9.56 \pm 8.94 \mathrm{bc}$ & $13.00 \pm 5.36 c$ & $8.27 \pm 6.13 a b c$ & $9.43 \pm 10.48 b c$ & $6.00 \pm 6.95 \mathrm{ab}$ & $5.28 \pm 6.66$ & 0.003 \\
\hline \multicolumn{8}{|c|}{ Interpersonal Distrust } \\
\hline $2.12 \pm 2.5 \mathrm{Ia}$ & $6.1 \mathrm{I} \pm 4.40 \mathrm{ab}$ & $7.89 \pm 5.06 b$ & $3.45 \pm 3.98 a$ & 4. $14 \pm 5.66 \mathrm{ab}$ & $3.00 \pm 3.30 \mathrm{a}$ & $3.39 \pm 3.87$ & $<0.001$ \\
\hline \multicolumn{8}{|l|}{ Perfectionism } \\
\hline $\begin{array}{l}5.88 \pm 3.7 \mathrm{Ia} \\
\text { Ineffectiveness }\end{array}$ & $8.22 \pm 5.33 \mathrm{ab}$ & \multicolumn{5}{|c|}{ Ineffectiveness } & $<0.001$ \\
\hline $2.00 \pm 3.79 \mathrm{a}$ & $1 \mathrm{I} .33 \pm 9.02 b$ & $13.33 \pm 8.66 \mathrm{~b}$ & $8.55 \pm 6.94 \mathrm{ab}$ & $10.86 \pm 12.24 b$ & $6.69 \pm 8.0 \mathrm{lab}$ & $5.83 \pm 7.74$ & $<0.001$ \\
\hline \multicolumn{8}{|c|}{ Body Dissatisfaction } \\
\hline $4.7 I \pm 4.55 \mathrm{a}$ & $16.44 \pm 8.4 \mathrm{Ib}$ & $18.44 \pm 10.18 b$ & $15.27 \pm 8.29 b$ & $12.29 \pm 9.56 \mathrm{ab}$ & I5.94 $\pm 7.75 b$ & $|0.32 \pm 8.8|$ & $<0.001$ \\
\hline \multicolumn{8}{|l|}{ Bulimia } \\
\hline $0.7 I \pm I .34 \mathrm{a}$ & $3.44 \pm 6.63 \mathrm{abc}$ & $6.67 \pm 3.08 c$ & $4.45 \pm 4.10 \mathrm{abc}$ & $2.14 \pm 2.91 \mathrm{ab}$ & $4.94 \pm 4.72 \mathrm{bc}$ & $2.62 \pm 3.88$ & $<0.001$ \\
\hline \multicolumn{8}{|c|}{ Drive For Thinness } \\
\hline $2.76 \pm 3.5 \mathrm{Ia}$ & $13.89 \pm 6.64 c$ & $|4.1| \pm 4.80 c$ & $12.45 \pm 6.28 c$ & $6.14 \pm 7.38 \mathrm{ab}$ & $\mid \mathrm{I} .3 \mathrm{I} \pm 5.54 \mathrm{bc}$ & $7.32 \pm 6.82$ & $<0.001$ \\
\hline \multicolumn{8}{|l|}{ General Score } \\
\hline $28.63 \pm 19.5 \mathrm{Ia}$ & $98 . I I \pm 58.58 b$ & $118.00 \pm 56.82 b$ & $88.55 \pm 47.58 b$ & $77.1 I \pm 71.85 b$ & $4 I .87 \pm 10.46 \mathrm{ab}$ & $59.03 \pm 50.4 I$ & $<0.001$ \\
\hline
\end{tabular}

Table 3 Participants scores in Barratt Impulsiveness Scale (Bis- I I)

\begin{tabular}{|c|c|c|c|c|c|c|c|}
\hline HC & AN-R & AN-BP & BN & Recovery & BED & Total & $\mathbf{p}$ \\
\hline$(n=5 I)$ & $(n=I I)$ & $(n=9)$ & $(n=12)$ & $(n=16)$ & $(n=16)$ & $(n=108)$ & \\
\hline \multicolumn{8}{|l|}{ Attention } \\
\hline $10.02 \pm 2.64$ & || $.64 \pm 3.4 \mid$ & $13.33 \pm 3.74$ & $10.75 \pm 3.79$ & $11.63 \pm 4.24$ & $10.25 \pm 2.64$ & $10.70 \pm 3.18$ & NS \\
\hline \multicolumn{8}{|c|}{ Attentional Impulsiveness } \\
\hline $16.29 \pm 3.74 a$ & $18.64 \pm 4.05 \mathrm{ab}$ & $21.56 \pm 4.69 b$ & $18.42 \pm 4.66 \mathrm{ab}$ & $19.25 \pm 5.80 \mathrm{ab}$ & $16.56 \pm 3.81 \mathrm{Ia}$ & $17.48 \pm 4.40$ & 0.009 \\
\hline \multicolumn{8}{|c|}{ Cognitive Instability } \\
\hline $6.27 \pm 1.63$ & $7.00 \pm 1.89$ & $8.22 \pm 12.00$ & $7.67 \pm 1.92$ & $7.63 \pm 2.26$ & $6.31 \pm 2.08$ & $6.78 \pm 1.88$ & 0.01 \\
\hline \multicolumn{8}{|c|}{ Non-Planning Impulsiveness } \\
\hline $22.78 \pm 4.45$ & $25.45 \pm 4.03$ & $27.11 \pm 4.16$ & $26.33 \pm 6.89$ & $24.38 \pm 3.11$ & $24.94 \pm 4.20$ & $24.26 \pm 4.76$ & 0.04 \\
\hline \multicolumn{8}{|c|}{ Cognitive Complexity } \\
\hline $10.39 \pm 2.57 \mathrm{a}$ & $12.73 \pm 2.14 \mathrm{ab}$ & $13.44 \pm 2.18 \mathrm{~b}$ & $12.75 \pm 3.13 \mathrm{ab}$ & $11.38 \pm 3.06 \mathrm{ab}$ & $12.50 \pm 2.12 \mathrm{ab}$ & $11.54 \pm 2.75$ & 0.001 \\
\hline Self-Control & & & & & & & \\
\hline
\end{tabular}


Table Continued..

\begin{tabular}{|c|c|c|c|c|c|c|c|}
\hline $\mathrm{HC}$ & AN-R & AN-BP & $\mathbf{B N}$ & Recovery & BED & Total & $\mathbf{p}$ \\
\hline$(n=5 I)$ & $(n=I I)$ & $(n=9)$ & $(n=12)$ & $(n=16)$ & $(n=16)$ & $(n=108)$ & \\
\hline $12.39 \pm 2.69$ & $12.73 \pm 3.13$ & $13.67 \pm 3.87$ & $13.58 \pm 4.27$ & $13.00 \pm 2.00$ & $12.44 \pm 3.38$ & $12.72 \pm 3.08$ & NS \\
\hline \multicolumn{8}{|c|}{ Motor Impulsiveness } \\
\hline $21.14 \pm 2.85 \mathrm{ab}$ & $19.45 \pm 4.69 \mathrm{a}$ & $25.33 \pm 5.26 b$ & $22.08 \pm 5.07 a b$ & $21.38 \pm 4.24 a b$ & $23.44 \pm 4.47 a b$ & $21.79 \pm 4.11$ & 0.012 \\
\hline \multicolumn{8}{|l|}{ Motor } \\
\hline $12.96 \pm 2.34 \mathrm{ab}$ & $12.55 \pm 4.05 a$ & $16.56 \pm 3.74 b$ & $14.00 \pm 4.45 \mathrm{ab}$ & $13.63 \pm 3.54 \mathrm{ab}$ & $15.19 \pm 3.63 \mathrm{ab}$ & $13.72 \pm 3.37$ & 0.017 \\
\hline \multicolumn{8}{|l|}{ Perseverance } \\
\hline $8.18 \pm 1.65$ & $6.91 \pm 1.81$ & $8.78 \pm 2.53$ & $8.08 \pm 1.62$ & $7.75 \pm 1.98$ & $8.25 \pm 2.01$ & $8.07 \pm 1.84$ & NS \\
\hline \multicolumn{8}{|l|}{ General Score } \\
\hline $60.21 \pm 8.30 \mathrm{a}$ & $63.54 \pm 10.44 \mathrm{ab}$ & $74.00 \pm 11.25 b$ & $66.83 \pm 14.30 \mathrm{ab}$ & $65.00 \pm 10.55 \mathrm{ab}$ & $10.08 \pm 2.52 \mathrm{ab}$ & $63.52 \pm 1.01$ & 0.006 \\
\hline
\end{tabular}

Table 4 Participants' scores in Go/No Go task

\begin{tabular}{|c|c|c|c|c|c|c|c|}
\hline $\mathrm{HC}$ & AN-R & AN-BP & $\mathbf{B N}$ & Recovery & BED & Total & $\mathbf{p}$ \\
\hline$(n=50)$ & $(n=10)$ & $(n=9)$ & $(n=\mid 2)$ & $(n=16)$ & $(n=16)$ & $(n=105)$ & \\
\hline \multicolumn{8}{|l|}{ Hit } \\
\hline $68.62 \pm 2.22 \mathrm{ab}$ & $69.70 \pm 0.48 b$ & $69.00 \pm 1.50 \mathrm{ab}$ & $69.25 \pm 0.86 b$ & $66.75 \pm 4.16 a$ & $69.06 \pm 0.92 \mathrm{ab}$ & $68.75 \pm 2.08$ & $\begin{array}{l}0.051- \\
\text { NS }\end{array}$ \\
\hline \multicolumn{8}{|l|}{ False Alarm } \\
\hline $1.80 \pm 1.48$ & $1.40 \pm 1.64$ & $2.67 \pm 1.87$ & $2.25 \pm 1.48$ & $2.25 \pm 1.16$ & $2.13 \pm 1.58$ & $1.97 \pm 1.52$ & NS \\
\hline \multicolumn{8}{|c|}{ Correct Rejection } \\
\hline $28.20 \pm 1.48$ & $28.60 \pm 1.64$ & $27.33 \pm 1.87$ & $27.75 \pm 1.48$ & $27.75 \pm 1.16$ & $27.88 \pm 1.58$ & $28.03 \pm 1.52$ & NS \\
\hline \multicolumn{8}{|l|}{ Miss } \\
\hline $1.38 \pm 2.22 \mathrm{ab}$ & $0.30 \pm 0.48 a$ & $1.00 \pm 1.50 \mathrm{ab}$ & $0.75 \pm 0.86 a$ & $3.25 \pm 4.16 b$ & $0.94 \pm 0.92 \mathrm{ab}$ & $1.25 \pm 2.08$ & $0.05 \mathrm{I}-\mathrm{NS}$ \\
\hline \multicolumn{8}{|l|}{ Mean Hit } \\
\hline $0.40 \pm 0.4 a$ & $0.44 \pm 0.06 \mathrm{ab}$ & $0.42 \pm 0.50 \mathrm{ab}$ & $0.4 I \pm 0.50 a$ & $0.4 I \pm 0.50 \mathrm{a}$ & $0.48 \pm 0.67 b$ & $0.42 \pm 0.05$ & $<0.001$ \\
\hline \multicolumn{8}{|l|}{ Mean False } \\
\hline $0.36 \pm 0.65$ & $0.36 \pm 0.02$ & $0.39 \pm 0.5$ & $0.37 \pm 0.88$ & $0.36 \pm 0.82$ & $0.36 \pm 0.10$ & $0.36 \pm 0.07$ & NS \\
\hline
\end{tabular}

Table 5 Correlations between participants' scores in the eating disorders inventory (EDI-2) and Impulsiveness scale (BIS) ( $\mathrm{n=I03)}$

\begin{tabular}{|c|c|c|c|c|c|c|c|c|c|}
\hline BIS / EDI-2 & Motor & $\begin{array}{l}\text { Self } \\
\text { Control }\end{array}$ & $\begin{array}{l}\text { Cognitive } \\
\text { Complexity }\end{array}$ & Perseverance & $\begin{array}{l}\text { Cognitive } \\
\text { Instability }\end{array}$ & $\begin{array}{l}\text { Attentional } \\
\text { Impulsiveness }\end{array}$ & Attention & $\begin{array}{l}\text { Motor } \\
\text { Impulsiveness }\end{array}$ & $\begin{array}{l}\text { Non-Planning } \\
\text { Impulsiveness }\end{array}$ \\
\hline Social insecurity & NS & NS & NS & NS & $\begin{array}{l}r=0.486 \\
p<0.001\end{array}$ & NS & NS & NS & NS \\
\hline $\begin{array}{l}\text { Impulse } \\
\text { regulation }\end{array}$ & NS & NS & NS & NS & NS & $\begin{array}{l}r=0.416 \\
p<0.001\end{array}$ & NS & NS & NS \\
\hline Asceticism & NS & NS & NS & NS & $\begin{array}{l}r=0.460 \\
P<0.001\end{array}$ & NS & NS & NS & NS \\
\hline Maturity fears & NS & NS & NS & NS & NS & NS & NS & NS & NS \\
\hline $\begin{array}{l}\text { Introspective } \\
\text { awareness }\end{array}$ & NS & NS & NS & NS & $\begin{array}{l}r=0.534 \\
p<0.001\end{array}$ & $\begin{array}{l}r=0.452 \\
p<0.001\end{array}$ & NS & NS & NS \\
\hline $\begin{array}{l}\text { Interpersonal } \\
\text { distrust }\end{array}$ & NS & NS & NS & NS & NS & NS & NS & NS & NS \\
\hline Perfectionism & NS & NS & NS & NS & $\begin{array}{l}r=0.444 \\
p<0.001\end{array}$ & NS & NS & NS & NS \\
\hline Ineffectiveness & NS & NS & NS & NS & $\begin{array}{l}r=0.500 \\
p<0.001\end{array}$ & $\begin{array}{l}r=0.462 \\
p<0.001\end{array}$ & NS & NS & NS \\
\hline $\begin{array}{l}\text { Body } \\
\text { dissatisfaction }\end{array}$ & NS & NS & NS & NS & NS & NS & NS & NS & NS \\
\hline Bulimia & $\begin{array}{l}r=0.459 \\
P<0.001\end{array}$ & NS & NS & NS & NS & NS & NS & NS & NS \\
\hline $\begin{array}{l}\text { Drive for } \\
\text { thinness }\end{array}$ & NS & NS & NS & NS & NS & NS & NS & NS & NS \\
\hline General score & NS & NS & NS & NS & $\begin{array}{l}r=0.508 \\
p<0.001\end{array}$ & $\begin{array}{l}r=0.420 \\
p<0.001\end{array}$ & NS & NS & \\
\hline
\end{tabular}

Table 6 Participants' scores in self-control questionnaire (SCS)

\begin{tabular}{|c|c|c|c|c|c|c|c|}
\hline $\mathrm{HC}$ & AN-R & AN-BP & $\mathbf{B N}$ & Recovery & BED & Total & $\mathbf{p}$ \\
\hline$(n=5 I)$ & $(n=I I)$ & $(n=9)$ & $(n=12)$ & $(n=16)$ & $(n=16)$ & $(n=107)$ & \\
\hline $123.59 \pm 16.043 b$ & $122.73 \pm 18.89 b$ & $95.78 \pm 19.99 a$ & $1 / 8.92 \pm 22.38 b$ & $114.50 \pm 19.19 a b$ & | | $4.63 \pm 19.78 \mathrm{ab}$ & $118.62 \pm 19.45$ & 0.003 \\
\hline
\end{tabular}




\section{Impulsivity}

The results of the Delay Discounting paradigm in a logarithmic scale are presented in Figure 1. Post-hoc Turkey test indicated a significant difference between AN-BP and the other groups $\mathrm{p}<0.05$. AN-BP subjects discounted delayed items remarkably more often than $\mathrm{HC}, \mathrm{AN}-\mathrm{R}, \mathrm{BN}$ and Recovery on day1 and then $\mathrm{HC}$ and Recovery on day7. No significant differences were found between groups on the $k$ parameter. For each group, mean indifference points were calculated and plotted value of delayed item, for each interval, for which there is no significant preference for either the immediate nor the delayed item. For each plot, an area under the curve AUC was calculated and a natural $\log$ was calculated L_AUC as a scatter-correction, due to small sample size. In a L_AUC*group ANOVA we found significant differences between groups in days 1, 7, 30, 60 and 90 . Day1 F5,101 $=4.173$, p=0.002, Day7 F5,101 $=3.335$, p $=0.008$, Day 30 $\mathrm{F} 5,101=2.744, \mathrm{p}=0.023$, Day60 F5,101 $=1.858, \mathrm{p}=0.108$ and Day90 $\mathrm{F} 5,101=2.355, \mathrm{p}=0.046$.

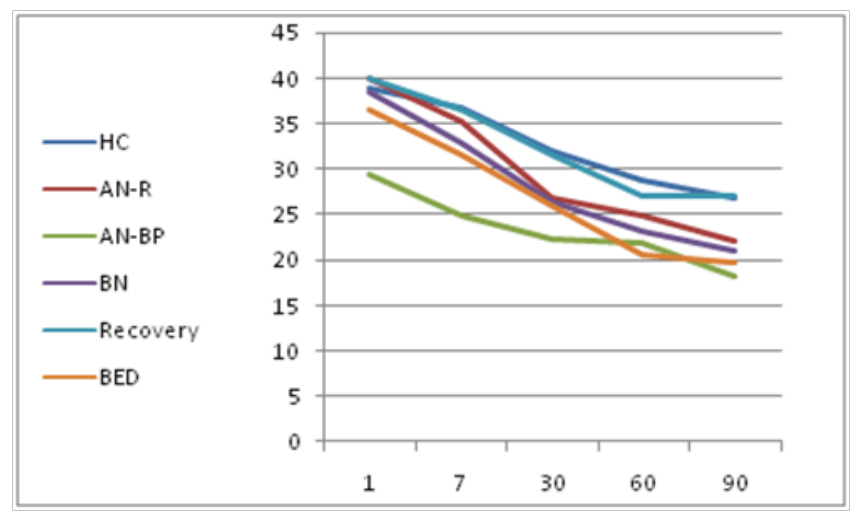

Figure I Delay discounting paradigm.

The BIS scores are presented in Table 3. Significant differences were noted in respect to attentional impulsiveness scores, cognitive instability, non-planning impulsiveness, cognitive complexity and motor impulsiveness. The healthy participants and the AN-R presented a significant lower impulsivity level in comparison to AN-BP group who presented the highest impulsivity level. BED and BN-P groups are located in the middle between these two extremities. No significant differences were found between groups concerning attention, self-control and perseverance scores.

The Go/No Go paradigm results are presented in Table 4. To evaluate reaction-inhibition factor, we used the subjects' mean reaction time for go-stimulus. We found that mean reaction time of BED 480(67) ms was significantly lower than that of the other groups $\mathrm{HC}=400(41) \mathrm{ms} ; \mathrm{BN}$ and recovery $=410(50) \mathrm{ms}$; $\mathrm{AN}-\mathrm{R}=440(61)$; $\mathrm{AN}-\mathrm{BP}=420(53) \mathrm{ms}$. Other variables measured did not show similar tendencies. The BED group was the slowest regarding the correct reactions.

\section{Relationships between Impulsivity and $f$ ED symptomology}

Despite the inability to deduce circumstantial relation based on the correlation tests, we tested the relations between eating disorders' symptoms intensity (EDI-2), impulsivity and self-control scores (BIS). There were statistically significant correlations between the EDI-2 subscale scores and cognitive instability and attentional impulsiveness (Table 5) .

Cognitive instability and attentional impulsiveness are in strong- moderate positive correlation $(0.4-0.5)$ in relation to most indexes that characterize eating disorder patients (EDI-2). The higher the attentional impulsiveness level is, the more acute the difficulty to regulate impulses, the higher the ineffectiveness and the introspective awareness. Furthermore, the higher the level of attentional impulsiveness, the higher the general score of EDI-2 questionnaire, which testifies of more acute eating disorder symptoms severity. Therefore, it was found that those presented the more severe cognitive instability, characterized in competitive and invasive thoughts, the higher the social insecurity, as well as the level of asceticism, perfectionism and ineffectiveness was found. As expected, a positive relation and a strong correlation were detected between high motor impulsiveness level and Bulimia's symptoms as well.

\section{Self-control}

No significant differences were detected in the MPQ scores . The results of SCS questionnaire are presented in Table 6. The HC group was found significantly higher than ED groups in self-control scorewhile AN-BP group scored the lowest.

\section{Association of weight categories and self- control categories}

Significant statistic differences were found between weight status groups and social insecurity, impulse regulation, asceticism, introspective awareness, interpersonal distrust, ineffectiveness, body dissatisfaction, bulimia, drive for thinness and general score (Table 7). Throughout the questionnaire the high and normal BMI groups scored the highest scores, meaning, cognitive and behavioral indexes of women with low weight in relation to eating disorders were the most severe, as expected. A tendency of positive relation between the lowest BMI group and between perfectionism and maturity fears was detected categories.

Significant differences were found between the weight categories and the self- control categories (Table 8): attention, cognitive complexity, attentional impulsiveness and general score. The low BMI group presented higher attention, cognitive complexity, attentional impulsiveness and general score in a significant manner compared to the normal and high BMI groups. No significant differences were found between the weight status groups and the MPQ and SCS scores.

\section{Discussion}

Previous studies have demonstrated deficits in decision making among eating disorders patients due to impulsive behavior and selfcontrol issues. Pathological eating behaviors such as anorexia, bulimia and obesity are characterized by a high preference for an immediate positive reward, despite the fact that such preference may lead to future physical and psychological damages. ${ }^{36-39}$ Anorexia patients severely limit their daily caloric consumption in order to obtain an immediate reward (easing the anxiety induced by food phobia) while ignoring the resulting damage. Similarly, Bulimia patients tend to harm themselves (binging/purging), such behavior results in immediate reward in the form of stress relief. Moreover, overweight patients tend to disregard future consequences (i.e. they may choose to eat too much, especially tasty food and rich calories despite the long term health hazards such as obesity, heart and blood vessels diseases, diabetes etc.). ${ }^{40}$

Most studies which investigated impulsivity among the different diagnosis groups did not differ between ED subtypes. This is the main attribute of our study which explored the differences between healthy, recovered and diagnosed ED patients in respect to impulsivity and self-control. 
Table 7 Participants' eating disorders inventory (EDI-2) scores according to weight

\begin{tabular}{|c|c|c|c|c|}
\hline BMI < I8.5 & BMI I 8.5 - 25 & BMI > 25 & Total & $\mathbf{p}$ \\
\hline$(n=8)$ & $(n=8 I)$ & $(n=18)$ & $(n=108)$ & \\
\hline \multicolumn{5}{|l|}{ Social Insecurity } \\
\hline $9.63 \pm 7.90 b$ & $3.44 \pm 4.32 \mathrm{a}$ & $2.78 \pm 3.35 \mathrm{a}$ & $3.8 I \pm 4.80$ & 0.001 \\
\hline \multicolumn{5}{|c|}{ Impulse Regulation } \\
\hline $9.63 \pm 9.84 b$ & $2.83 \pm 4.38 a$ & $4.1 I \pm 5.08 \mathrm{a}$ & $3.58 \pm 5.35$ & 0.002 \\
\hline \multicolumn{5}{|l|}{ Asceticism } \\
\hline $10.25 \pm 7.83 b$ & 4. $18 \pm 5.19 a$ & $5.67 \pm 3.88 \mathrm{a}$ & $4.91 \pm 5.43$ & 0.008 \\
\hline \multicolumn{5}{|l|}{ Maturity Fears } \\
\hline $5.50 \pm 4.69$ & $4.86 \pm 4.37$ & $4.67 \pm 2.84$ & $4.87 \pm 4.14$ & NS \\
\hline \multicolumn{5}{|c|}{ Introspective Awareness } \\
\hline $1 \mathrm{l} .75 \pm 8.77 \mathrm{~b}$ & $4.57 \pm 6 . \mathrm{I} \mathrm{Ia}$ & $5.44 \pm 6.73 a$ & $5.28 \pm 6.66$ & 0.013 \\
\hline \multicolumn{5}{|c|}{ Interpersonal Distrust } \\
\hline $7.38 \pm 6.04 b$ & $3.08 \pm 3.56 \mathrm{a}$ & $2.94 \pm 3.15 \mathrm{a}$ & $3.39 \pm 3.87$ & 0.009 \\
\hline \multicolumn{5}{|l|}{ Perfectionism } \\
\hline $10.00 \pm 5.58$ & $7.16 \pm 4.57$ & $5.50 \pm 2.43$ & $7.09 \pm 4.45$ & NS \\
\hline \multicolumn{5}{|l|}{ Ineffectiveness } \\
\hline $13.75 \pm 11.10 \mathrm{~b}$ & $4.87 \pm 6.93 a$ & $6.44 \pm 7.7 \mathrm{Ia}$ & $5.83 \pm 7.74$ & 0.007 \\
\hline \multicolumn{5}{|c|}{ Body Dissatisfaction } \\
\hline $17.38 \pm 12.52 b$ & $8.53 \pm 7.83 a$ & $|4.83 \pm 8.2| \mathrm{ab}$ & $|0.32 \pm 8.8|$ & 0.001 \\
\hline \multicolumn{5}{|l|}{ Bulimia } \\
\hline $4.50 \pm 4.03 \mathrm{a}$ & $1.97 \pm 3.50 \mathrm{a}$ & $4.56 \pm 4.60 \mathrm{a}$ & $2.62 \pm 3.88$ & 0.013 \\
\hline \multicolumn{5}{|c|}{ Drive For Thinness } \\
\hline $12.75 \pm 7.57 b$ & $6.01 \pm 6.53 a$ & $10.50 \pm 5.72 \mathrm{ab}$ & $7.32 \pm 6.82$ & 0.002 \\
\hline \multicolumn{5}{|l|}{ General Score } \\
\hline I I $2.50 \pm 78.22 b$ & $5 \mathrm{I} .5 \mathrm{I} \pm 45.57 \mathrm{a}$ & $67.44 \pm 42.06 a$ & $59.03 \pm 50.41$ & 0.003 \\
\hline
\end{tabular}

Table 8 Participants' impulsiveness scores (BIS) according to weight categories

\begin{tabular}{|c|c|c|c|c|}
\hline $\mathrm{BMI}<18.5$ & BMI I $8.5-25$ & BMI > 25 & Total & $\mathbf{P}$ \\
\hline$(n=9)$ & $(n=8 I)$ & $(n=18)$ & $(n=108)$ & \\
\hline \multicolumn{5}{|l|}{ Attention } \\
\hline $14.11 \pm 3.18 b$ & $10.45 \pm 3.10 \mathrm{a}$ & $10.1 \mathrm{I} \pm 2.6 \mathrm{Ia}$ & $10.70 \pm 3.18$ & 0.003 \\
\hline \multicolumn{5}{|c|}{ Attentional Impulsiveness } \\
\hline $22.67 \pm 4.63 b$ & $17.28 \pm 4.28 \mathrm{a}$ & $16.28 \pm 3.81 \mathrm{a}$ & $17.48 \pm 4.40$ & 0.007 \\
\hline \multicolumn{5}{|c|}{ Cognitive Instability } \\
\hline $7.56 \pm 2.06$ & $6.83 \pm 1.80$ & $6.17 \pm 2.03$ & $6.78 \pm 1.88$ & NS \\
\hline \multicolumn{5}{|c|}{ Non-Planning Impulsiveness } \\
\hline $26.22 \pm 4.41$ & $23.94 \pm 4.92$ & $24.72 \pm 4.12$ & $24.26 \pm 4.76$ & NS \\
\hline \multicolumn{5}{|c|}{ Cognitive Complexity } \\
\hline $13.22 \pm 2.48 \mathrm{a}$ & $1 \mathrm{I} .18 \pm 2.83 \mathrm{a}$ & $12.33 \pm 2.08 \mathrm{a}$ & II.54 1.75 & 0.042 \\
\hline \multicolumn{5}{|l|}{ Self-Control } \\
\hline $13.00 \pm 3.57$ & $12.76 \pm 3.02$ & $12.39 \pm 3.25$ & $12.72 \pm 3.08$ & NS \\
\hline \multicolumn{5}{|c|}{ Motor Impulsiveness } \\
\hline $24 . I I \pm 5.94$ & $21.26 \pm 3.70$ & $22.94 \pm 4.45$ & $21.79 \pm 4.11$ & NS \\
\hline \multicolumn{5}{|l|}{ Motor } \\
\hline $14.78 \pm 4.63$ & $|3.38 \pm 3.1|$ & $14.72 \pm 3.69$ & $13.72 \pm 3.37$ & NS \\
\hline \multicolumn{5}{|l|}{ Perseverance } \\
\hline $9.33 \pm 2.17$ & $7.89 \pm 1.72$ & $8.22 \pm 2.01$ & $8.07 \pm 1.84$ & NS \\
\hline \multicolumn{5}{|l|}{ General Score } \\
\hline $72.00 \pm 12.85 b$ & $62.47 \pm 9.93 a$ & $63.94 \pm 10.19 \mathrm{ab}$ & $63.52 \pm 10.47$ & 0.033 \\
\hline
\end{tabular}

Though using rather small sample size, significant differences were presented in the cognitive as well as in motor impulsivity between the study groups. There was a hierarchy of occurrence of impulsivity in the different categories of eating disorders. Cognitive impulsivity as well as motor impulsivity and global score of impulsivity were most prominent in the AN-BP group. The healthy participants demonstrated the lowest impulsivity while the other groups were in between. In congruence with our findings Claes et al., ${ }^{41}$ noted that among patients with anorexia nervosa those with binge purging type showed higher levels of impulsivity compared to restricting type patients. ${ }^{42}$

In our study, those individuals who currently had an eating disorder at the time of assessment and those who already recovered were respectively $23 \%$ and $8 \%$ more likely to be impulsive than the healthy group participants. This trend has been demonstrated via the BIS score and the delay discounting task. This hierarchy was correlated with the eating disorders symptoms as viewed by EDI in the different 
groups. This is in contrast to other studies which reported that $\mathrm{BN}$ patients had higher scores in EDI comparing to AN patients as well as reports that did not found any correlations between self-reported and behavioral measures of impulsivity across ED subtypes. ${ }^{41,43}$

Moreover, we observed that impulsivity was associated with more purging behaviors and not only among those diagnosed with $\mathrm{BN}$ as was reported by Favaro et al., ${ }^{44}$ Similar to our study, others found that the binge groups (i.e., ANP, BN) showed more motor impulsiveness ${ }^{45-47}$ and inattention ${ }^{41}$ in comparison to healthy control group.

There are reports linking impulsivity ${ }^{48}$ as well as purging behaviors in ED to greater overall morbidity and worse outcome. ${ }^{49}$ Some suggested that dysfunctional interactions between serotonin and dopamine systems in the prefrontal cortex may be an important mechanism underlying the link between impulsivity and ED symptoms. ${ }^{3,7}$ This may also explain the higher rate of relapse observed in our study in the AN-BP group. Favaro et al., ${ }^{44}$ suggested that purging behavior is actually an important predictor of the presence and number of impulsive behaviors. Those in the non-purging bulimia nervosa group showed a lowered prevalence of impulsive behaviors.

In our study the AN-BP group demonstrated higher scores in social insecurity, introspective awareness, interpersonal distrusts, perfectionism and bulimic symptoms in comparison to all other groups. Social insecurity, introspective awareness and perfectionism were highly correlated with cognitive impulsivity $(\mathrm{r}=0.44-0.53$, $\mathrm{p}<0.001)$.

Motor impulsivity was highly correlated with bulimic symptoms $(\mathrm{r}=0.46, \mathrm{p}<0.001)$. Thus it is not surprising that motor impulsivity was higher among those that binge. The lowest score was observed among AN-RS and the highest among AN-BP while all other groups were in between.

Impulsivity has evaluated not only by self-report but also in the delay discounting task. The AN-BP demonstrated significantly different behavior in short term delays in comparison to other groups of participants. In short term reward trials, AN-BP patients were less willing to delay gratification in comparison to other participants who demonstrated preference for the higher delayed reward.

In long term reward trials, no differences were observed among groups. This may explain the AN-BP group higher symptomatic scores as observed by EDI. The cognitive impulsivity as measured by the delay discounting task demonstrated that those with the lower BMI overestimated the value of the immediate reward and under evaluation of the delayed reward. Batterink et al., ${ }^{6}$ reported that those with lower weight status may suffer from psycho-motor slowness which may be interpreted as lower impulsivity in behavioral tasks while in self- report tools this slow- down is not expressed.

Still, for those with AN-R restricting food yields immediate reward of relief which might be due to the reduction in serotonergic level as was explained by Keys et al. Moreover, those with lower weight status demonstrated less attention, more cognitive complexity and more attentional impulsiveness. Preoccupation with food and weight may explain these results. Lower weight is associated with higher preoccupation among restricting healthy subjects as has been previously showed in the Minnesota study ${ }^{50}$ as well as among ED patients. $^{4}$

With regard to response inhibition, in contrast to Rosval et al., ${ }^{47}$ who reported that the AN-BP demonstrated higher rates of false alarm which is attributed to motor impulsivity, in our study the Go/No Go task did not yield significant differences among groups. Claes et al., ${ }^{41}$ also did not find a significant increase in Disinhibition or lack of inhibitory control between controls and the ED groups.

The impulse regulation and the ineffectiveness scores of both AN groups were higher in comparison to the other groups. These two variables were highly correlated with attentional impulsiveness which may explain their higher score in drive for thinness. Their attention is highly responsive to thinness although significantly different than that of the BED, recovered and healthy subjects.

Although the consistency of the higher impulsivity of AN-BP group in comparison to the other diagnosis groups, this study suggests that impulsivity and self-control cannot be used as a discriminating factor between different diagnoses rather than be suited on continuous axis. Normal weight participants demonstrated a high level of selfcontrol and a low level of cognitive and motoric impulsivity, while underweight participants demonstrated a high level of impulsivity. It should be noted that a high level of impulsivity was also observed among recovered ED participants, which may indicate the presence of an inherent personal trait beyond the symptomatic impulsive state. Neuro-behavioral studies have previously suggested that dysfunctional interactions between serotonin and dopamine systems in the prefrontal cortex may be an important mechanism underlying the link between impulsivity and its comorbid disorders. ${ }^{3}$ Bulimic patients were found to be carrying particular genes that were responsible for not only greater impulsivity, but also for lower levels of serotonin in bloodstream, possibly indicating that the genetic predisposition influences both serotonin production as well as impulsivity. ${ }^{51}$

Due to the small sample size and the nature of the case-control cross sectional study we cannot predict the specific contribution of impulsivity to the development of ED. This question should be addressed via prospective longitudinal studies which are scarce. If impulsivity will be recognized as a risk factor for the development of ED, this issue should be included in ED preventive programs. The relationship between impulsivity, self-control and symptoms of EDs imply that treatment should target the components of impulsivity and self-control to reduce the intensity symptoms and accelerate recovery. Different strategies should be developed when targeting motor impulsivity (mainly in those with binging) vs. cognitive impulsivity.

This study had several limitations. First, since it is a communitybased case-control study it does not determine cause-and-effect relationships between different variables and unable to include data on confounding factors. It typically includes only females from middle class socio economic status - individuals with specific characteristics and thus represents a minority of those suffering from ED which limits the generalizability of the findings. There also may have been a sampling bias in that participants recruited from the community may be less impulsive than those assessed during an inpatient setting.

Secondly, the small sample size limited the analysis performed and also might impact the outcome. Since we were not able to move the time or age effect the conclusions should be interpreted cautiously. In respect to the assessment methods, the computerized tasks measured responsiveness to reward and inhibition response were administered in a relatively neutral environment, and did not take into account factors that may affect impulsivity (e.g. autonomic arousal; Enticott et al. 2006), and thus may have limited generalizability. The self-report questionnaires have the inherent problem of individuals denying the presence and/or severity of symptoms as well as cognitive distortions. Despite these limitations the study contributes to understanding the relationship between EDs subtypes, ED symptoms and impulsivity.

The study strengths include the distinction between ED subtypes, allowing to explore differences in impulsivity across the groups. In 
contrast to many other studies, this study included a matched group of normal controls with which the behaviors of the eating-disordered could be compared as well as recovered participants. This study had used multiple methods to measure impulsivity, combination of behavioral tasks and self- report measures.

\section{Conclusion}

These findings suggest that bingeing and restricting behaviors may be seen as lying on the opposite ends of a spectrum of impulsive behaviors. Individuals with AN-BP appear to have more in common with $\mathrm{BN}$ individuals as they share the tendency to display greater response Disinhibition and produce more impulsive behaviors. Bingeing/purging behavior is an important predictor of, and appears to be associated with impulsive behaviors, not the ED diagnosis (AN or $\mathrm{BN}$ ). The findings need to be replicated in future research using consistent ED samples and objective instruments, as well as using larger sample sizes. To assess the role of impulsivity as a risk factor for the development of an eating disorder, a prospective longitudinal studies should be held.

\section{Acknowledgments}

None.

\section{Conflicts of interest}

Author declares there are no conflicts of interest.

\section{Funding}

None.

\section{References}

1. Lacey JH (1993) Self-damaging and addictive behavior in bulimia nervosa. Br J Psychiatry 163: 190-194.

2. Lilenfeld LR, Wonderlich S, Riso LP, Crosby R, Mitchell J (2006) Eating disorders and personality: A methodological empirical review. Clin Psychol Rev 26(3): 299-320.

3. Kaye WH, Fudge JL, Paulus M (2009) New Insights into Symptoms and Neurocircuit Function of Anorexia Nervosa. Nat Rev Neurosci 10(8): 573-584.

4. Afifi-Soweid RA, Najem Kteily MB, Shediac-Rizkallah MC (2002) Preoccupation with weight and disordered eating behaviors of entering students at a university in Lebanon. Int J Eat Disord 32(1): 52-57.

5. American Psychiatry Association (2000) Diagnostic and Statistical Manual of Mental Disorders, text revision, DSM-IV-TR (4th edn). Washington DC, USA.

6. Batterink L, Yokum S, Stice E (2010) Body mass correlates inversely with inhibitory control in response to food among adolescent girls: An fMRI study. Neurolmage 52(4): 1696-1703.

7. Rogers RD, Tunbridge EM, Bhagwagar Z, Drevets WC, Sahakian BJ, et al. (2003) Tryptophan depletion alters the decision-making of healthy volunteers through altered processing of reward cues. Neuropsychopharmacology 28(1): 153-162.

8. Cavedini P, Bassi T, Ubbiali A, Casolari A, Giordani S, et al. (2004) Neuropsychological investigation of decision-making in anorexia nervosa. Psychiatry Res 127(3): 259-266.

9. Tchanturia K, Liao PC, Uher R, Lawrence N, Treasure J, et al. (2007) An investigation of decision making in anorexia nervosa using the Iowa Gambling Task and skin conductance measurements. J Int Neuropsychol Soc 13(4): 635-641.
10. Boeka AG, Lokken KL (2006) The Iowa gambling task as a measure of decision making in women with bulimia nervosa. J Int Neuropsychol Soc 12(5): 741-745.

11. Brand M, Franke-Sievert C, Jacoby GE, Markowitsch HJ, TuschenCaffier B (2007) Neuropsychological correlates of decision-making in patients with bulimia nervosa. Neuropsychology 21(6): 742-750.

12. Liao PC, Uher R, Lawrence N, Treasure J, Schmidt U, et al. (2009) An examination of decision-making in bulimia nervosa. J Clin Exp Neuropsychol 31(4): 455-461.

13. Svaldi J, Brand M, Tuschen-Caffier B (2010) Decision-making impairments in women with binge eating disorder. Appetite 54(1): 8492.

14. Duchesne M, Mattos P, Appolinário JC, de Freitas SR, Coutinho G, et al. (2010) Assessment of executive functions in obese individuals with binge eating disorder. Rev Bras Psiquiatr 32(4): 381-388.

15. Baumeister R, Heatherton T (1996) Self-Regulation Failure: An Overview. Psychological Inquiry 7(1): 1-15.

16. Hofmann W, Friese M, Strack F (2009) Impulse and Self-Control from a Dual-Systems Perspective. Perspect Psychol Sci 4(2): 162-176.

17. Baumeister RF, Bratslavsky E, Muraven M, Tice DM (1998) Ego Depletion: Is The Active Self a Limited Resource? J Pers Soc Psychol 74(5): 1252-1265.

18. Fishbach A, Friedman RS, Kruglanski AW (2003) Leading Us Not To Unto Temptation: Momentary Allurements Elicit Overriding Goal Activation. J Pers Soc Psychol 84(2): 296-309.

19. Fishbach A (2009) The Dynamics of Self-Regulation. In Forgas J, Baumeister, R, Tice D (Eds.), Psychology of Self-Regulation: Cognitive, Affective and Motivational Processes. Psychology Press, New York, USA, pp. 163-181.

20. Patton JH, Stanford MS, Barratt ES (1995) Factor Structure of the Barratt Impulsiveness Scale. J Clin Psychol. 51(6): 768-774.

21. Claes L, Vandereycken W, Vertommen H (2005) Impulsivity-Related Traits in Eating Disorder Patients. Personality and Individual Differences 39(4): 739-749.

22. Waxman SE (2009) A Systematic Review of Impulsivity in Eating Disorders. Eur Eat Disord Rev 17(6): 408-425.

23. First MB, Spitzer RL, Gibbon M, Williams JB (1997) Structured Clinica Interview for DSM-IV Axis I Disorders SCID I: Clinician Version. American Psychiatric Press, Washington DC, USA.

24. Garner D (1991) The Eating Disorder Inventory-2: Professional Manual. Psychological Assessment Resources, Odessa, Florida.

25. Niv N, Kaplan Z, Mitrani E, Shiang J (1998) Validity study of the EDI2 in Israeli population. The Isr J Psychiatry Relat Sci 35(4): 287-292.

26. Leshem R, Glicksohn J (2007) The Construct of Impulsivity Revisited. Personality and Individual Differences 43(4): 681-691.

27. Spinella M (2007) Normative Data and a Short Form of the Barratt Impulsiveness Scale. Int J Neurosci 117(3): 359-368.

28. Tangney JP, Baumeister RF, Boone AL (2004) High Self-Control Predicts Good Adjustment, Less Pathology, Better Grades, and Interpersonal Success. J Pers 72(2): 271-324.

29. Tellegen A, Waller N (1985/2008) Exploring Personality through Test Construction: Development of the Multidimensional Personality Questionnaire. In: Boyle G, Matthews G, \& Saklofske D (Eds.), The SAGE Handbook of Personality Theory and Assessment, The Cromwell Press LTD, Trowbridge, England, pp. 261-292.

30. Ben-Porath Y, Almagor M, Hoffman-Chemi, A, Tellegen A (1995) A Cross-Cultural Study of Personality with the Multidimensional Personality Questionnaire. Journal of Cross-Cultural Psychology 26(4): $360-373$. 
31. Mazur J (1987) An adjusting procedure for studying delayed reinforcement. In: Commons $\mathrm{M}$, Mazur ., Nevin $\mathrm{J}$ \& Rachlin $\mathrm{H}$ (Ed.), Quantitative Analysis of Behavior: The Effect of Delay and of Intervening Events of Reinforcement Value. Erlbaum: Hillsdale, New Jersey, 5: 55-73

32. Tesch A, Sanfey A (2008) Models and Methods in Delay Discounting. Ann N Y Acad Sci 1128: 90-94.

33. Mitchell SH (1999) Measures of Impulsivity in Cigarette Smokers and Non-Smokers. Psychopharmacology 146(4): 455-464.

34. Donders F (1969) On the Speed of Mental Processes. In: Koster W (Ed.), Attention and performance II, Amsterdam: North-Holland, pp. 412-431.

35. Verbruggen F, Logan GD (2008) Autonomic and Controlled Response Inhibition: Associative Learning in the Go/No-Go and Stop-Signal Paradigms. J Exp Psychol Gen 137(4): 649-672.

36. Duchesne M, Mattos P, Appolinário JC, de Freitas SR, Coutinho G, et al. (2010) Assessment of executive functions in obese individuals with binge eating disorder. Rev Bras Psiquiatr 32(4): 381-388.

37. Brogan A, Hevey D, Pignatti R (2010) Anorexia, bulimia, and obesity: Shared decision making deficits on the Iowa Gambling Task (IGT). J Int Neuropsychol Soc 16(4): 711-715.

38. Guillaume S, Sang CN, Jaussent I, Raingeard I, Bringer J, et al. (2010) Is decision making really impaired in eating disorders?. Neuropsychology 24(6): 808-812.

39. Brogan A, Hevey D, O’Callaghan G, Yoder R, O’Shea D (2011) Impaired decision making in morbidly obese adults. J Psychosom Res 70(2): 189-196.

40. Epstein LH, Salvy SJ, Carr KA, Dearing KK, Bickel WK (2010) Food reinforcement, delay discounting and obesity. Physiol Behav 100(5): 438-445.

41. Claes L, Nederkoorn C, Vandereycken W, Guerrieri R, Vertommen H (2006) Impulsiveness and lack of inhibitory control in eating disorders. Eat Behav 7(3): 196-203.
42. Claes L, Vandereycken W, Vertommen H (2005) Self-care versus selfharm: piercing, tattooing, and self-injuring in eating disorders. European Eating Disorders Review 13: 11-19.

43. Clausen L, Rosenvinge JH, Friborg O, Rokkedal K (2011) Validating the Eating Disorder Inventory (EDI-3) in two Danish samples: A comparison between 561 female eating disorders patients and 878 females from the general population. J Psychopathol Behav Assess 33(1): 101-110.

44. Favaro A, Zanetti T, Tenconi E, Degortes D, Ronzan A, et al. (2005) The relationship between temperament and impulsive behaviors in eating disordered subjects. Eat Disord 13(1): 61-70.

45. Díaz-Marsá M, Carrasco JL, Basurte E, Sáiz J, López-Ibor JJ, et al (2008) Enhanced cortisol suppression in eating disorders with impulsive personality features. Psychiatry Res 158(1): 93-97.

46. Kane TA, Loxton NJ, Staiger PK, Dawe S (2004) Does the tendency to act impulsively underlie binge eating and alcohol use problems? An empirical investigation. Personality and Individual Differences 36(1): 83-94

47. Rosval L, Steiger H, Bruce K, Israël M, Richardson J, et al. (2006) Impulsivity in women with eating disorders: Problem of response inhibition, planning, or attention? Int J Eat Disord 39(7): 590-593.

48. Boisseau CL, Thompson-Brenner H, Eddy KT, Satir DA (2009) Impulsivity and personality variables in adolescents with eating disorders. J Nerv Ment Dis 197(4): 251-259.

49. Deter HC, Herzog W (1994) Anorexia nervosa in a long-termperspective: results of the Heidelberg Mannheim study. Psychosom Med 56(1): 2027.

50. Keys A, Brozek J, Henschel A, Mickelsen O, Taylor HL (1950) The Biology of Human Starvation. Univ. of Minnesota Press, Minneapolis, USA, vol. I and II.

51. Steiger H, Gauvin L, Israël M, Koerner N, Ng Ying Kin NM, et al. (2001) Association of serotonin and cortisol indices with childhood abuse in bulimia nervosa. Arch Gen Psychiatry 58(9): 837-843. 